\title{
Microscopic examination of ancient and modern irrigated paddy soils in South Korea, with special reference to the formation of silty clay concentration features
}

\author{
Lee, H., ${ }^{1}$ French, C. ${ }^{2}$ and Macphail, R. I. ${ }^{3}$ \\ 1: Institute for Archaeology and Environment, Korea University, Sejong City, South Korea \\ (ddangpa@korea.ac.kr) \\ 2: Department of Archaeology and Anthropology, University of Cambridge, Cambridge \\ (caif2@cam.ac.uk) \\ 3: Institute of Archaeology, University College London, London (r.macphail@ucl.ac.uk)
}

\begin{abstract}
Geoarchaeological investigations of Bronze Age (10th-4th Centuries BC), early historical (4th to 10th Centuries AD), and pre-modern to modern paddy soils (15th century AD to contemporary) in South Korea were carried out to understand soil alteration by irrigated rice agriculture. After a review of ancient cultivation micromorphology, especially in the context of wet rice agriculture, paddy soils were examined from two representative archaeological sites, Gulhwa and Pyunggeo, which had been both intermittently occupied since the Bronze Age. This paper highlights some apparently anomalous pedofeatures (silty clay concentration features or SCCF) repeatedly observed in both historical and modern paddyfields, and which were studied using soil micromorphology, energy dispersive X-ray spectrometry (EDS) and microprobe analysis. Results suggest that there are several associated types of SCCF, optically distinguishable from other textural pedofeatures. It is concluded that these SCCF are probably associated with hydromorphic processes, formed under the influence of a tillage and irrigation regime specific to paddy fields.
\end{abstract}

\section{INTRODUCTION}

Rice nurtured many ancient civilizations and wet-rice farming still sustains much of the world's population. The distinguished cultivation method of rice is the paddyfield, a naturally or constructed waterlogged field imitating the natural habitat of rice, a semiaquatic plant. Forms of paddyfields vary, ranging from natural flooded alluvial plains (fluxial??, lowland) to terraced fields with water supplement systems (irrigated), while upland rice (fluvial, phreatic) does not have flooding phases different from other the types (fluvial anthraquic, phreatic anthraquic) (Moormann \& Van Breemen, 1978). The type of rice cultivation method is determined mainly by climate and landscape variables (De Datta, 1981), but advanced techniques in historical times allowed land-use of alternating (dry) upland rice cultivation and paddy rice cultivation; multi- rotational cropping of rice paired with barley, millet, legumes to improve soil productivity and sustainability of rice farming by adding nutrients derived from other crops, was also carried out. While constrained by climate, landscape and soil type, diversified rice cultivation was innovated and developed over time.

Domestication of rice occurred in the naturally flooded lowlands along the River Yangtze since at least c. $7000 \mathrm{BP}$ in China. Later, an artificial habitat for rice was produced by constructing earth banks to maintain areas of standing water, and thus the paddyfield was invented. Paddyfield agriculture, which is usually known as the submerged rice farming field method, subsequently spread to all of Northeast Asia (Fuller \& Qin, 2009). In the Korean peninsula, rice was introduced in Neolithic times (c. 5000-4000 BP) at the earliest, but its cultivation began and became popular during the Bronze Age (c. 1300-300 BC) (Ahn, 2010). 
The presence of rice agriculture was postulated not only by carbonised rice remains, but also by buried rice fields discovered through excavation. Starting from the end of Early Bronze Age with associated field system irrigation features, paddy rice cultivation continued to achieve technical sophistication in terms of cultivation tools, soil fertility management, and locally connected large scale irrigation systems throughout the historical period (4th-10th Centuries AD). Over these periods through to present times, rice has been the main agricultural crop of Korea (Ahn, 2010; Kwak, 2002).

The distinguished features attributable to Bronze Age paddy rice cultivation consisted of a bunded or embanked field system, which is a field system enclosed by low upright banks (bunds) to store water and to create rare small reservoirs and irrigation canals in Korea (H.-J. Lee, 2003). Bunded or terraced paddyfields were common from the Bronze Age to Three Kingdoms/Unified Silla Periods (Kwak, 2010). During the early stage of paddyfield cultivation, rice was grown on rain-fed fields, but in the later period, frequent switching between in-field flooding and drainage was practiced at the crucial points of the rice growing cycle, such as before panicle formation and final drainage until the harvest in Autumn. Even during the flooding period, there is periodic draining of the fields for weeding in between planting and harvest time, in order to enhance the rice grain growth by allowing additional air into the soil system. This scheme called Sukyeongbeop, 'water cultivation' was the most widely practiced irrigation/flood regime, which is thought have spread during the Unified Silla period. In the early historical period, large-scale local reservoirs were constructed to supply irrigation water required for this intermittent drainage and re-saturation regime, which might have contributed to an increase in rice productivity (Jeon, 2010; Kwak, 2010). In the historical period, fertility of the fields was enhanced by the addition of straw, growing legumes and applying manure mixed with fermented human and animal faecal waste and various plant residues and herbs; iron rich clay soil could also be added to recover old and degraded paddy soils (Kwak, 2002; H.-H. Lee, 2010).

Compared to numerous ethnoarchaeobotanical and genetic research on rice remains and on paddyfields summarised by Fuller \& Qin (2009) and Fuller et al. (2010), the effect of tillage and cultivation activities on ancient paddysoils has been little studied in soil science. The most commonly recognized paddy soil characteristics are redoximorphic features such as iron hypo-coatings and iron-manganese (Fe-Mn) nodules, which are common indicators of periodic water saturation and soil drying (Janssen \& Lennartz, 2007; Kyuma, 2004; Lindbo et al., 2010; Stoops \& Eswaran, 1985; Vepraskas et al., 1994). Other generally observed geochemical characteristics nutrient flow models. This includes (Greenland, 1997; KögelKnabner et al., 2010; KimA et al., 2010; Kirk, 2004; Kyuma, 2004; Tout \& Argosino, 1985; Weiner, 2010; Wissing et al., 2011) in the paddy soils of the temperate and subtropical climatic zones: $\mathrm{N}$ (nitrogen) mineralization coupled with soil organic matter, the concentration of dissolved organic matter and associated methane emission. In addition, there is the increase in $\mathrm{Fe}^{3+}$ organic matter complexes, redoximorphic effects on iron oxides and associated weathering of clay minerals, together with the formation of a depleted groundmass, and horizontal differentiation within the soil profile by the movement of iron and manganese. The last can lead to iron pan development. Except for iron which can become fixed, the accumulation of chemical elements is highly variable due to in/outflow of irrigation water, which often causes a loss of soluble nutrients and elements (Prakongkep et al., 2008; Wang et al., 2003). Hence a few studies indicate that the accumulation of elements such as Si and Zn may vary in each micro-stratigraphic unit (Egashira et al., 1997).

Physical changes occur in soil microstructure, and resulting vugh-shape depends on soil 
composition and how it is influenced by wetting/drying processes (Eickhorst \& Tippkötter, 2009; Ringrose-Voase et al., 2000). Puddling (or wet tillage) turns and mixes the soil under waterlogged conditions. Wet ploughing is known to destroy soil aggregates and clods, because it lowers the strength of these; translocation of the resulting dispersed fine particles of soil may create a traffic or plough pan at the base of the cultivated layer as mobilised silt and clay accumulate (Dexter \& Woodhead, 1985; Janssen \& Lennartz, 2007). Plough pans (or compacted layers) then often resist root penetration by subsequent crops, causing localised waterlogging, and the formation of large clods in finer-textured soils when ploughed (Greenland, 1997; Sanchez \& Buol, 1985).

Paddy soils are subject to two types of modification mechanisms, associated with the specific combination of agriculture and hydromorphic conditions. The effect of irrigation practices on soil may be theoretically different from seasonal submergence and drying because the waterlogging period is artificially prolonged for few months in the paddy soil, and includes intermittent drainage and re-saturation; this enhances the growth of rice plants and remove toxic matter such as sulphuric acid (Cheng, 1984) while allowing time for weeding (Jeon, 2010). In addition, the soil undergoes a long period of drying out after harvesting. Another effect observed as a consequence of the long-term use of paddy fields in Southeast China, is the depletion of calcium carbonate $\left(\mathrm{CaCO}_{3}\right)$ (Chen et al., 2011). In South Asia, the destruction of clay through leaching of displaced cations often causes a silica concentrated horizon by ferrolysis (Brinkman, 1970, 1977).

Despite the variability and dynamics of rice cultivation practices and its historical importance, little is known about micromorphological features of silt and clay movement in long-term paddy rice cultivation whereas reports focus on various forms and sizes of ironmanganese nodules induced by both natural or anthropogenic flooding regimes (Adderley et al., 2010; Kovda, 2010). Rare thin section studies have shown that features such as light gray silty-clay quasi-coating form below the plough pan (Y. He et al., 2008) and skeletal grain fabrics and complex calcium carbonate nodules (Xu \& He, 2009) develop in the calcareous paddy fields of South-east China. Notably, studies have also reported that silt concentrations form in the clay matrix with zones of diffuse extinction in areas of oriented clay, for example in Thailand paddysoils (Miura et al., 1992). Nonetheless, case study examples of microscopic analyses - here phytolith microfossils - of ancient and modern paddyfields are still very rare (Barnes, 1990). With the above listed investigations of paddyfield as a baseline for this present archaeological and micromorphological investigation, research focused on paddy soils from various periods in order to identify micromorphological soil changes associated with paddy soil cultivation. It has also been recently reported that buried paddy soil layers, as old as the Neolithic in Yangtze River Delta region, China, these are identifiable from organic chemical markers including cadelene probably released from rice plant residues (Zhang et al., 2013).

Rescue excavations in advance of housing developments at two archaeological sites in South Korea, Gulhwa and Pyunggeo where Bronze Age (c.10th-4th Centuries BC), historical (c. Three Kingdoms Period: 4th to 7th Centuries AD; Unified Silla Period: 8th-10th Centuries AD) were carried out. The presence of pre-modern to modern (c. Koreyo and Joseon Dynasties: 11th-20th Centuries AD) paddyfield horizons were also recognized (Figures 1 \& 2) and allowed the geoarchaeological investigation of associated buried paddy field soils (Table 1).

These excavations afforded the opportunity to examine a number of possible in situ paddy 
soils from a micromorphological perspective, supported by energy dispersive X-ray spectrometry (EDS) and microprobe analyses (Goldberg \& Macphail, 2006, 362-366; KögelKnabner et al., 2010). This paper describes a number of particular pedogenic features which are repeatedly discovered in ancient and modern rice paddy soils in South Korea and one modern example of a contemporary paddyfield soil from Yongjeong (Yongjung), Cheonan for comparison. Interpretations of ancient agricultural practices are based on analogy with pedofeatures produced by modern agricultural techniques and soil conditions and the examination of ancient buried agricultural soils and features produced by experiments (Gebhardt, 1993, 1995; Goldberg \& Macphail, 2006; Pagliai et al., 2004; Simpson, 1997; Usai, 2001). This also included the modern paddysoil study database employed in the above review.

\section{The Gulhwa site}

The Gulhwa site is located on the edge of the floodplain formed by the River Taehwa flowing to the East Sea, $20 \mathrm{~km}$ inland from the seashore. A large part of the city, Ulsan to which the Gulhwa site belongs, is situated on land aggraded on the river downstream due to the alluvium transported by the River Taewha since the Holocene Flandrian transgression. A subsequent minor recession and transgression detected at 3000 B.P. had affected the formation of the flood plain (Hwang \& Yoon, 2000). The River Taehwa meanders slightly as a result of river migration and the accumulation of fluvial deposits, forming a flat floodplain. Except for the narrow floodplain along the riverside, most of the land is mountainous and linked to Mount Munsu (552m above sea level). The Gulhwa site is situated on the back of a levee, and at the junction between the bottom of the low-lying hills and the floodplain (Figure 2a). From the Bronze Age, settlement sites and paddyfields developed, such as Ockhyun, known to be the earliest Bronze Age paddyfield site in Korea (dated to 10th Century BC); this is characterised by small grided fields that are densely concentrated in this river floodplain (Kim, 2004). In the historical period, this area became a local transport focus, and was recorded as "Gulhwahyun" in the Three Kingdom's period until the political authority shifted to local government in Koryeo Dynasty period (Ulsan Cultural Property Institute, 2008). Excavation at the Gulhwa site revealed two Bronze Age houses, and associated paddyfield systems. Early Historical paddyfield systems and the remains of associated roads were also found (Figure 2b).

The cross-section of the main soil profile at Gulhwa site exhibits a discrete type of palaeosolsedimentation sequence (Fedoroff et al., 2010) with each stratified horizon dated by pottery typology and associated archaeological features. The main soil profile consists of a basal gravel bed overlain by a darkish horizon. A second darkish layer after an interval of noncultural sedimentation, and is followed by recently accumulated alluvium. Its date was determined from associated pottery typology and radiocarbon dates on the Bronze Age house of the 10th to 9th Centuries BC. The first darkish layer is a Bronze Age paddyfield horizon (Figure 1) with a small bunded to retain water $\left(3.3 \mathrm{~m}^{2}\right)$. The second darkish, historical period layer is associated with terraced fields of the Unified Silla-Koryeo Dynasties and only partially survives (Figure 2b). This second anthropogenic horizon was enclosed by the remains of a unified Silla period pebbled road. The overlying orange-yellowish silt loamy layer above the early historical paddy horizon is the pre-modern to modern cultural layer (Figures $2 \mathrm{c} \& 2 \mathrm{~d}$ ). Historical and pre-modern horizons were also indicated by phytolith analysis which showed high concentrations of fan-shaped bulliform rice phytoliths, with $>5,000$ per gram (Ulsan Cultural Property Institute, 2008). Unfortunately, investigation of the field features in this horizon was not carried out due to the Korean convention of not 
excavating pre-modern to contemporary fields. Part of the site was also being used as a modern paddyfield and the surface soil is classified as Udalf (based on a classification of the Rural Development Administration's soil information digital map: http://asis.rda.go.kr/). Two independent locales (GSA and GSC units) were selected for sampling from a profile across the south of this Gulhwa site (located in Figure 2b). The elevation of the site is 16-18m asl. The average annual temperature of this area is $14.1{ }^{\circ} \mathrm{C}$ and has an annual precipitation of $1,277 \mathrm{~mm}$.

\section{The Pyunggeo site}

The Pyunggeo site is one of series of multi-period complex prehistoric and early historical settlements located alongside the River Nam, at Jinju city, Kyungnam Province, South Korea. The city, Jinju is situated in a basin surrounded by a series of connected mountains ranging between $200-400 \mathrm{~m}$ in altitude. The basin is underlain by the Cretaceous bedrock and infilled with Holocene fluvial deposits River Nam origin. This river runs through the middle of the city and flows to the South Sea. The River Nam, comprising many small tributary streams, turns into a large and meandering river in its lower reaches as flow velocity diminishes. The high sinuosity of the river developed wide sandy under-cut and slip-off slopes where prehistoric and historical settlements including the Pyunggeo site, are mainly located; Pyunggeo sites 3-1 (Figure 3a) share a similar landscape. Geomorphological survey conducted at the Pyunggeo site reveals that the River Nam was a braided sandy river stream 10000-12000 years ago. Since then the river begun to have a highly sinuous meandering course, creating sandy levees and wide flood plains on both sides of the river. The backswamp and oxbow lakes where the paddyfield is located, began to fill 6000 years ago.

The elevation of the site is $27-30 \mathrm{~m}$ asl. The average annual temperature of this area is $11.7^{\circ} \mathrm{C}$ and has an annual precipitation of $1,316.8 \mathrm{~mm}$.

However, the floodplain of the River Nam has been inhabited since the Paleolithic, but more archaeological emphasis was put on the large Bronze Age dry fields and complex settlements. In the 1990's a large-scale excavation was conducted by a team from several universities prior to the construction of the Jinyang Dam and reservoir along the middle part of the River Nam. This revealed a set of massive dry fields, dwelling pits and burials of various periods, dating to the Neolithic (settlement only), the Early and Late Bronze Age, the proto-Kingdoms (0-3th centuries AD), the Three Kingdoms, and pre-Modern periods (Dong-Ah University Museum, 1999). In the 2000's extended excavation took place on the floodplain of the River Nam to the southeast of the Jinyang Dam in advance of housing development, which included the discovery of the Pyunggeo site. In Area A where the sampling point was located, 69 Neolithic dwellings, 129 Bronze Age dwelling pits, burials and two identified cultivated fields (Figure 3b) were found. Also 155 dwelling pits, four paddy horizons (Figure 3c) and one dry field horizon of the Three Kingdoms period (5th-7th centuries AD), as well as two pre-modern (Joseon Dynasty; 15th-20th centuries AD) paddy horizons and burials were excavated. Prior to the excavation, the surface was used as a paddyfield. Area A in Sites 3-1 is divided into three micro-geomorphological units. In the south, there is a large flood plain where the dry field consists of elongated ridges and furrows. Next to the dry field, a slightly elevated sand ridge is present, and almost all dwellings of the various periods are situated there. Behind the sandy ridge, paddyfields are located in the former backswamp area.

The cross-section profile across the site (Figure 3d) exhibits a sequence of cumulic type palaeo-sedimentation beneath a thick sandy flood deposit (Fedoroff et al., 2010). The relative 
date of each horizon was determined by associated pottery and contextual evidence from excavation (Figure 3). Samples were collected from the long cross-sectional trench cut through the eastern part of excavated paddy fields of District A. The Ap horizon soils record the present day paddy field and are classified as Aquepts (Rural Development Administration's soil information digital map: http://asis.rda.go.kr/).(Center of History and Culture, 2011). Seven intact block samples were taken for micromorphological analysis from the Bronze Age horizon upwards, including the historical and modern field horizons. The Bronze Age paddy horizon overlies clayey alluvium., 91 field units $\left(5-58.8 \mathrm{~m}^{2}\right)$ without clear bunds were preserved in the Bronze Age paddy field district The Three Kingdoms paddy horizon overlies the Bronze Age paddy horizon. The Three Kingdoms paddy fields comprise fields of various sizes. They have a well preserved terraced and bunded field system (87$150 \mathrm{~m}^{2}$ to $675-1,120 \mathrm{~m}^{2}$ ), and these preserve both footprints and hoof marks of cattle; ploughmarks were also abundant across the whole paddy field surface (Figure 3e). Part of the paddy field was later transformed into a dry field, as indicated by the discovery of ridge and furrows overlying the relicts of the paddyfield system with its bunding and irrigational canals. Such overlapping dry field and paddy field systems are often discovered, because crop rotation or field type switching were often carried out to during this period (Kwak 2002). Thus in this Ap horizon, three sectors of dry field, paddy field, and a dry field converted from a wet paddy field, survived well. Practical constraints, however, only allowed sampling within the paddy field system. This Three Kingdom's period paddy field was covered by a thick flood-derived sandy deposit $(22-30 \mathrm{~cm}$ thickness). Above these flood sands, there are pre-modern, modern and contemporaneous paddy field horizons.

\section{Modern Reference}

At the Yongjeong-ri site, Cheonan, one sample was collected from the underlying soil of an abandoned paddy field, and used as contemporary paddy soil reference material. The sampling area was situated at the end of the floodplain basin, which was created by the Bonggang stream (Chungcheong Cultural Property Institute, 2008) (Figure 4). The surface soil was classified as Udalf.

\section{METHODS}

There were two soil profiles from the Gulhwa site and one soil profile from the Pyunggeo site. Bulk samples were collected from the main stratigraphic horizons of each profile. Box samples were collected from the horizons covering the prehistoric (Bronze Age), historical (The Three Kingdom's and Unified Silla Dynasties), pre-modern/modern phases (Koryeo and Joseon Dynasties), as dated by pottery and archaeological features, with the aim of examining ancient and historical paddysols.

$\mathrm{pH}$ was measured in a 2:5 soil water suspension ratio using a $\mathrm{pHep} 2$ electronic $\mathrm{pH}$ meter. Particle size distribution analysis using a Malvern Mastersizer 2000 was carried out at the Physical Geography Laboratory, University of Cambridge, UK. In addition to these standard methods, soil micromorphology, microprobe and Energy Dispersive X-Ray (EDS) analyses were employed. Soil micromorphology was used to identify various components of the soil matrix as well as pedogenic processes (Schaetzl \& Anderson, 2005; Stoops et al., 2010). Intact block samples were examined using soil micromorphological analysis (Courty et al., 1989). The blocks were impregnated with resin and manufactured into $130 \mathrm{~mm}$ long thin sections at the McBurney Geoarchaeology Laboratory, Division of Archaeology, University of Cambridge, the UK. Descriptions were made according to accepted terminology of 
Bullock et al. (1985) and Stoops (2003).

EDS and microprobe analyses on the GSC 7 thin section impregnated blocks (pre-modern paddyfield soil) from the Gulhwa site were specifically employed to determine the chemical components of anomalous dusty clay features, called silty clay concentration features (abbreviated to SCCF)(Goldberg \& Macphail, 2006; Schaetzl \& Anderson, 2005). EDS and microprobe examinations were carried out at the Institute of Archaeology, University College, London, to determine the chemical composition of the entire GSC 7 profile.

\section{RESULTS}

\section{Bulk soil and soil micromorphological analyses}

Field observations of the Gulhwa site profile 1 (GSA) and profile 2 (GSC), and the Pyunggeo site profile $(\mathrm{PG})$ are reported in Table 1 . The results of the thin section study are presented in Tables $2 \& 3$, together with those of the geophysical analyses. Field and grain size data indicate that the paddy soils at the Gulhwa and Pyunggeo sites are composed of fine silt loams over a clay loam alluvium and $\mathrm{pH}$ is either neutral, between $\mathrm{pH}$ 6-8. Upwards it is more variable, and slightly acid in places ( $\mathrm{pH}$ 5-7). Micromorphological analyses revealed that both the ancient and modern paddy soils exhibit a similar massive microstructure and a low porosity often in the form of polyconcave vughs. The dominant depletion pedofeature is the iron-depleted groundmass, while cryptocrystalline pedofeatures are composed of amorphous iron-manganese, iron, and manganese nodules and impregnations (staining). Numerous complex textural pedofeatures including dusty clay features, double-layered coatings, anomalous dusty clay features termed silty clay concentration features (SCCF; Figure 6) are observed in the researched thin sections. This paper specifically notes the different occurrences of SCCF in Bronze Age, the Three Kingdom's and Unified Sillahistorical period paddy field soils, in comparison to the modern paddy field Ap horizon reference material. There is also a variety of anthropogenic inclusions in the paddy soils, including concentrations of micro-charcoal and unarticulated phytoliths including bulliform rice phytolith types. The latter were identified in thin section, although their recognition and identification in thin section does however depend on the colour of the groundmass) (Fisher et al., 1995; Itzstein-Davey et al., 2007; Zheng et al., 2003). The composition of coarse sandsized mineral observed in the all thin sections consists of dominant quartz, occasional to many biotite mica and feldspar, with some of the last showing surface weathering. This composition is consistent from the base of the soil profile, upwards.

\section{Identification and Classification of the 'silty clay concentration features' (SCCF)}

During the optical examination of thin sections of ancient and modern paddy soils, a number of anomalous dusty clay features were repeatedly observed. As the characteristics of these anomalous features appear to be correlated, they have been termed 'silty clay concentration features' (or SCCF; Figure 6) and hereafter are referred to as such. They are characterised by a homogeneous internal fabric, a stipple specked b-fabric with very low interference colours (under XPL), regularly sorted silt-size mineral particles, silt-sized organic inclusions, and a pale to yellowish clay matrix (PPL); sometimes they exhibit isotropism (XPL). Although it is understood that concentrations of silt-sized materials in a water-saturated soil environment, the very regular and uniformly arranged silt particle distribution pattern that has a high density and a sharp boundary in the groundmass, clearly differentiates these SCCF (Figure 6a), from similarly looking textural pedofeatures such as matrix intercalations in the 
descriptive guides of Bullock et al. (1985) and Stoops (2003). In addition, they do not belong to any of the typical hydromorphic features or dusty textural pedofeatures created by cultivation activities. Although some of the SCCF exhibit an iron-depleted ('reduced') pale coloure, they are not completely whitish alban/neoalban features typically created by hydromorphic soil conditions. In addition, the arrangement of silt sized particles differs from the dusty clay infillings and crusts induced by cultivation. These characteristics appear to distinguish SCCFs from typical textural and hydromorphic features as described elsewhere in the wider literature addressing redoximorphic features (Lindbo et al., 2010) and those in some palaeosols within alluvial sequences examined elsewhere in the region such as at Chongokni in the Imjin River Valley, South Korea (Macphail, 2010). Lastly, these features are observed in both the Gulhwa and Pyunggeo thin sections and in the modern Yongjeong paddy field sample. Three types of SCCF were observed (Figure 6). Type X has a relatively pale clayey matrix. Its internal fabric is characterised by uniformly sorted silt-sized organic matter, silt and clay, and in some cases mica flakes, but these have very low and atypical interference colours. A variant called type XA (Figure 6a) is either formed as aggregates in the groundmass or is present as coarse fragment infillings in the voids and are sub-rounded and sub-angular in shape, with diffuse boundaries. Sometimes type XA occurs as a horizontal lens in the groundmass. The composition of the internal fabric varies, and sometimes the clay matrix is isotropic. A second variant, type XB, (Figure 5b) refers to a fragmented and translocated papule of the type XA fabric embedded within the groundmass, and this has a sharp boundary.

Type Y (Figures $6 \mathrm{c}$ and $6 \mathrm{~d}$ ) with an internal fabric like type $\mathrm{X}$, occurs with more associated clayey and iron features. Some have developed into concentric iron nodules. The variant type YA (Figure 5c) is characterised by an impure clayey fabric. Colours are speckled dark reddish brown, (PPL), with low interference colours (in XPL) and are orange, red speckled (in OIL). Another sub-variant, type YB (Figure 5d), resembles intercalated clay within the groundmass. Type Z (Figure 5e) is similar to type X, but exhibits more silt-sized charcoal, and is relatively poorly sorted. It occurs as an infilling with diffuse boundaries, and. The size of organic particles is coarser $(>10 \mu \mathrm{m})$ that are more irregularly distributed than in type X.

\section{Micromorphological features from Gulhwa}

\section{The Gulhwa site}

The two parallel profiles (referred as GSA and GSC) through Bronze Age, Unified Silla and pre-modern to modern period paddy field horizons exhibit changes in pedofeatures (Tables 2 and 3). In thin section, the basal gravel-bed has a vughy structure resulting from silt and clay that has been washed into voids between gravels. The first darkish paddy soil layer, which is dated to the Bronze Age, is a silty clay loam with a dense and micro-charcoal enriched groundmass. Highly intensive hydromorphic processes are indicated by abundant iron and manganese nodules of concentric and halo types. There are also coalesced iron aggregates, with inclusions of soils and organic matter fragments. The horizon is also characterised by a partially depleted groundmass with zones of elutriated silt and fine sand-sized particles. In this horizon, a massive microstructure and polyconcave vughy porosity might reflect the repeated water saturation of the soil and its subsequent structural collapse (Boersma \& Kooistra, 1994; Bresson \& Moran, 2004) The paddysol also exhibits abundant textural pedofeatures including laminated crescentic coatings and infillings of dusty silty clay; depositional crusts and iron micro-pans are formed and have been incorporated into the groundmass. These textural pedofeatures could have resulted from surface disturbance and 
associated internal slaking. Soils under the influence of agriculture commonly exhibit dusty clay coating/infillings and crescentic compound infillings. These coatings and infillings with silt size particles or size-sorted laminated compound layers can occur alongside various types of structural crusts (Jongerius, 1983; Macphail et al., 1990). Micro-charcoal and minute organic fragments are scattered across the groundmass and phytoliths of various shapes, including clearly identified rice bulliform phytoliths, are observed in the groundmass along with very rare minute bone fragments. These inclusions can be interpreted as resulting from either anthropogenic cause associated with farming practice (Adderley et al., 2010; Goldberg \& Macphail, 2006; Nicosia et al., 2011) or deposition transported from the river (Brown, 1997). As well as exhibiting clear redoximorphic conditions in the form of iron-manganese nodules, this horizon appears to have been subject to intensive surface disturbance, indicated by various dusty clay features and the iron-manganese nodules, which have developed into concentric and halo types, which have inclusions of soil and organic matter fragments; this has been as observed in the other paddy soils (Hseu et al., 2010).

The deposit overlying the Bronze Age field is yellowish silt loam (in GSA 3 and GSC 3 sections; Table 2). Although redoximorphic conditions continue upwards as demonstrated by the presence of iron-manganese nodules and occasional formed elutriated silt zones, there is in contrast a less dense groundmass, an increase in coarse particles, and less micro-charcoal compared to underlying and overlying horizons. In addition, crescentic clay coatings and infillings are absent, which indicates a better drained and less disturbed horizon. There is, however, a very rare occurrence of SCCF type Z, the development of which might have been influenced by the overlying historical paddy soil horizon.

The early historical (Unified Silla; 7th-10th centuries AD) buried paddy field horizon (GSA 4 and GSC 4 sections-Table 2) is a massive structured silty loam with polyconcave vughs. Ironmanganese nodules and staining are predominant, but compared to the Bronze Age horizon, structural infillings, and the frequency and intensity of nodule formation are less. A proportion of charred and uncharred vegetal fragments such as stem fragments increase, with phytoliths visibly embedded in the groundmass. Horizontal crusts/crescentic infillings $(4 \mathrm{~mm}$ in size) are present, and some occur with highly abundant micro-charcoals, causing the black colour of this layer. There are various abundant dusty clay coatings, which are strong indicators of surface disturbance by cultivation activities (Courty et al., 1990). Such features are created by the mobilized silt and clay, as also happens in paddy fields through both wet and dry tillage activities (Greenland, 1997; Moormann \& Van Breemen, 1978). The most noticeable change is the clearer occurrence of SCCF pedofeatures. Their uniform pale/isotropic clayey internal fabric distinguishes them from the groundmass and from typical dusty clay coatings (Figures 6a and 6c). Given the excavation context of the layer where the paddy field system was discovered, this horizon clearly indicates an agricultural soil is present. This is consistent with the occurrence of crusts and dusty clay features, and increased macro and micro organic matter, as well the many iron and manganese nodules and stainings formed under wet soil conditions. It also shows the context of the initial stage of SCCF formation.

In the upper part of the soil profile at the GSA and GSC locations, there seems to be a major difference in land use patterns exhibited through microstructural change. The GSA unit exhibits very compacted but weakly-developed lenticular peds and a lack of clear SCCF development. The platy structure may suggest the presence of a trampled and compressed zone such as a pathway or residential area (Courty et al., 1989; Ge et al., 1993; Gebhardt \& Langohr, 1999; Goldberg \& Macphail, 2006) Noticeably there is an intact 3mm thick silty 
and phytolith rich whitish band, marking deposition rather than cultivation or other disturbance. Iron staining features are horizontally aligned. In contrast, the same unit in the GSC profile shows no sign of compression, and exhibits a massive micro-structure with polyconcave vughs. The groundmass is an iron depleted pale clay, with occasional impregnative iron staining. SCCFs are abundant and types XA, XB, YA, YB, and Z, occur, alongside associated dusty clay features and horizontal silt inwash features. Coarse organic matter increases in the form of unoriented parenchymatous tissues scattered in the groundmass. In addition, iron replaced plant fragments occur, together with both macro- and micro charcoal; various forms of phytoliths including rice bulliforms, were identified. Lastly, rare to occasional iron nodules and much iron staining is present.

\section{Micromorphological features from Pyunggeo}

At the second site, Pyunggeo, the substratum is a dense clayey to silty clay loam (Table 2), probably formed in alluvium infilling an abandoned palaeochannel (Ryu et al., 2008). In the subsoil and Bronze Age horizons (PG 1), the many iron nodules and impregnative staining, and abundant amorphous organic matter/humus present might indicate both the moderately organic rich and fertile nature of the soil and prolonged wet soil formation conditions. The particularly dark colour derives from humification of the organic residues and incomplete decomposition of plant materials, which implies mostly wet conditions, and often humic-silty infillings are found in such submerged paddy fields (Kovda, 2010). A few relict patches of unsorted laminae point to undisturbed initial sedimentation in the form of mud deposition. The clear division between the upper and the lower parts of the thin section, which is the basal part of the Bronze Age paddy soil is recognisable from the sharp and impermeable boundary with which has more clay and organic matter; iron nodules also formed along this boundary. One faunal burrow exhibits depositional crusts as compound layered infillings.

Hints of surface disturbance and alteration are more prominent at the Bronze Age/early historical horizons (PG 2, PG 3 and the lower half of PG 4). The rare silty clay concentration feature (SCCF) type YA and occasionally type Z occur with occasional laminated clay and sandy crusts that are $3 \mathrm{~mm}$ in thickness. However, there is a possible mixing of the soil influenced by later historical cultivation, as occurs in welded soils (Holliday, 2004). Thus the first SCCF appear in the Bronze Age at the earliest and in the early historical Three Kingdoms period (3-7th centuries $\mathrm{AD}$ ) at the latest.

The obvious historical buried paddy field horizon (PC 3) shows an increase of SCCF type $\mathrm{XA}$, often formed with silt size mica flakes. SCCF type XB, and occasional to many type YA, also occur. Occasional sand crusts and fragments of sorted crusts and decreased amounts iron-manganese features in the groundmass are observed. A sandy flood alluvium sealing the paddy soil surface is predominantly composed of coarse quartz sand grains, muscovite, biotite, and rare feldspar (Figure 6). This flood deposit exhibits an enaulic (intergrain aggregate) coarse:fine distribution with occasional embedded clay balls ( $1 \mathrm{~mm}$ in size) occurring that are made up of clay, phytoliths and organic matter and few sand grains. There are no obvious coatings on sand grains. The presence of a flood deposit (in the upper part of PG 4) which seals the paddy soil surface (in the lower part of PG 4), means that all the SCCF pedofeatures must have formed within the underlying buried paddy fields (Figure 6c), at the time when the paddy field was in use.

In the pre-modern/modern horizon (thin sections PG 5 and 6), there are abundant silty clay concentration feature types XA and XB (3mm in size), and occasional SCCF Type XA with 
more silt sized mica flakes. Rare SCCF types XB and YA, blackish ferro-manganese hypocoatings and rare to occasional iron-manganese nodules with micro-charcoal and plant residues are also present. Possible implement features characterised by an amorphous iron accumulation zone occur along the feature-infilled boundary at the relative thin section depths $5.5 \mathrm{~cm}$ and $2.5 \mathrm{~cm}$ in sample PG 6 . The infilling of the feature is more organic rich and darker than the surrounding matrix soil.

\section{The modern reference sample}

The thin section sample from the abandoned field in Yongjeong, is a massive structured silt loam with a few weakly developed platy peds in the upper part. It exhibits abundant silty clay concentration features as well as iron hypo-coatings indicative of redoximorphic conditions. SCCFs include many type XA (up to $7 \mathrm{~mm}$ in size with mica flakes) (Figure 5e), occasional type XB, many type $Y$ and rare type $Z$. These associated pedofeatures are similarly present in the upper part of the profiles at the Gulhwa and Pyunggeo sites, which are also representative of modern/contemporary paddy field horizons.

\section{ENERGY DISPERSIVE X-RAY SPECTROMETRY (EDS) AND MICROPROBE ANALYSES}

Microprobe analysis on the GSC 7 thin section was focused upon typical paddy soil microfeatures in order to determine the chemical components of SCCF. Results (Figure 7) show: 1) areas of clay-poor matrix soil (i.e. low silicon and aluminium) formed by fine soil dispersion and loss, under water saturated paddy soil conditions, and 2) a strongly contrasting area rich in aluminium and silicon, which developed through dispersed clay and silt forming local textural intercalations and infill features. Element mapping also demonstrated that iron (Figure 7c) occurs as probable secondary neoformed (precipitated) features associated with the precipitation of phosphorous and calcium, as also indicated by EDS (Table 4). The top part of thin section is rich in silicon and low in aluminium, consistent with the process of aluminium leaching and silicon accumulation (Figures 7a, b \&c).

EDS results (Figure 7) shows that SCCF type XA exhibits a minor increase (c. 5\%) in $\mathrm{Si}$, a decrease of $\mathrm{Al}$ (to $c .2 \%$ ) and $\mathrm{Fe}(c .5-6 \%$ ) on average as compared to the adjacent siltier clay groundmass matrix without SCCF (Table 4). In contrast, in the SCCF type YB, Si is less (to c. $5 \%$ ) and $\mathrm{Fe}$ increases (to $c .5 \%$ ) compared to the matrix average. It can also be noted that no Mn was found, confirming that this element is apparently totally lost from this water saturated plough zone. Examples of iron stained and iron-poor matrix soil at the top of the section showed that these have a low clay content ( $\mathrm{Al}, \mathrm{Si}, \mathrm{Mg}, \mathrm{K}$ ), consistent with the micromorphology. The exact process responsible for these differences remains to be further investigated, but there does appear to be change in the proportions of elements present at both the horizon and specific feature scale.

\section{DISCUSSION AND CONCLUSIONS}

\section{Formation hypothesis of SCCFs}

The examination of the selected ancient and modern paddy field soils reveals that paddy soil formation processes are recorded by the presence of various textural pedofeatures and iron and manganese cryptocrystalline features. This, probably reflects hydromorphic conditions, linked to a water saturated soil environment, which was also affected by surface and sub- 
surface disturbance. The latter includes tillage, and any associated trampling by people and animals, planting etc. The resulting disturbance features and organic inputs have been described above, and are consistent with other workers findings (see Introduction). On the other hand, SCCFs, which have been identified have not previously been reported. Microprobe and EDS analysis of the soil properties of SCCF lead us to postulate formation process. The first characteristic of SCCF is a dense concentration of silt size. Movement and concentration of silt-sized particles is the most representative phenomena of intensive surface and sub-surface disturbance and associated internal slaking. A number of researchers have noted that several common features are observed in archaeological and modern agricultural soils. These include increased surface disturbance (Courty et al., 1989; Gebhardt, 1995; Goldberg \& Macphail, 2006; Macphail et al., 1990; Usai, 2001), loosening and subsequent aggregation of soil particles (Jongerius, 1983; Sharma \& de Datta, 1985) and increased heterogeneity due to inclusions of mixed extraneous materials, and compaction by tillage tools in some parts of the plough soil (Lewis, 1998).

The highly dispersed silt materials which include micro-charcoal in textural pedofeatures, is commonly observed in cultivated paddy soils (Y. He et al., 2008; Miura et al., 1992) where both wet and dry period tillage takes place (Greenland, 1997; Moormann \& Van Breemen, 1978). These fine inclusions may reflect a general increase of included silt-sized and fine organic matter derived from a wide variety of agricultural activities associated with soil disturbance. Rare soil micrormorphological studies on paddy fields also report concentrations of silty particles in the clay-depleted coatings or as embedded material in the groundmass. Unfortunately, wider comparisons with long-term paddy soils in China, for example, is not possible as these studies usually lack full micromorphological description and analysis. Nonetheless, grey silty-clay quasi-coatings have been observed (Y. He et al., 2008). Residual clay as aggregates in the groundmass also occurs in irrigated and cultivated non-paddy soils, and irrigation increases its proportion (Pang et al., 2007). The second characteristic is a uniformly speckled arrangement of silt-sized particles while the third characteristic is a pale clay matrix without any oriented clay, as in the case of type X. In particular, type XA tend to have a low $\mathrm{Fe}$ and high $\mathrm{Si}$ content. Also types $\mathrm{X}$ and $\mathrm{Z}$ are formed with isotropic/pale or slightly reddish clay matrix, and are likely associated with clay alteration under hydromorphic conditions. A variety of reduced/iron-depleted neoformed clay features that are reported in the literature are mainly generated by hydromorphic processes in the seasonally saturated soils. These include: 1) albic neoskeletan, grainy gray ped coatings, grainy void cutans, silans, and skeletans; 2) skeleton grains in the iron and manganese-depleted eluvial clay with a high silicon content (Chartres, 1987; McCarthy et al., 1999; Vepraskas \& Wilding, 1983); 3) alban and neo-alban features defined by low iron content, gray colour, and their assimilation into the adjacent groundmass - as developed from hypo-coatings that merge into the ped interior (Veneman et al., 1976; Vepraskas et al., 1994), and 4) clay depletion features or partially altered dusty clay coatings (Brinkman et al., 1973; Chartres, 1987; McCarthy et al., 1999). In some cases, repeated wetting and drying also leads to the destruction of clay through leaching of displaced cations, creating a whitish Si rich horizon or altered dusty clay features with Si (Brinkman, 1970, 1977). Silica or silicon is the one parameter that reflects ferrolysis since the destruction of clay tends to favour an unusual and consequential accumulation of silicon (Brinkman, 1970; Jongerius, 1970). In seasonally wet and drained soils, the formation of gray, depleted textural pedofeatures at the small scale with a silicacemented horizon at the large scale has been previously observed (Aufiousseau, 1990; Barbiero et al., 2010; Boixadera et al., 2003; Chartres, 1987; McDaniel et al., 2001; Ransom et al., 1987). Thus, there is a possibility that such chemical changes which develop the high $\mathrm{Si}$ and low Al content in SCCF might be accounted for by typical paddy field soil processes, 
linked specifically to ferrolysis (Brinkman, 1970; Kyuma, 2004; Schaetzl \& Anderson, 2005).

The occasional presence of iron in type $\mathrm{X}$ or in type $\mathrm{Y}$ which is highly iron impregnated and where it forms as aggregates, coatings and infillings, is notable. Similar phenomena were reported in the development of both a pale coatings with high silicon and iron-rich coatings in palaeosols appearing to have been affected by periodic wetting and drying, with consequent chemical changes to $\mathrm{Si}, \mathrm{Al}$, and Fe content (McCarthy et al., 1999). Given the long-term waterlogging association with irrigation which certainly promotes frequent changes in the redoximorphic environment (De Datta, 1981; Yukawa, 1989), the two impregnative iron types of SCCF X and Y may be related to movement of iron as a characteristic of hydromorphic soils, whereas many of type $\mathrm{X}$ exhibit iron-depleted clay matrix. The occasional occurrence of isotropic clay in SCCF type X appears to result from leaching of iron and aluminium and an increase of silica. A higher silica content in some SCCF type X is also suggested by the EDS results (Table 5), and the concentration of silicon in the horizon separate from aluminium and iron was noted by the microprobe analysis in section GSC 7 where abundant SCCF types are present (Figure 7).

In addition, there is one piece of contextual evidence indicating that SCCF are not mere products of just hydromorphic conditions in that there is a lack of SCCF in the Bronze Age buried palaeosol in Gulhwa. This soil contains more concentric types of iron-manganese nodules and exhibits a highly iron-depleted groundmass, which suggests a long phase of repeated redoximorphic conditions (X. He et al., 2003; Lindbo et al., 2010; Lindbo et al., 2004; Severson et al., 2008). Under similar conditions of $\mathrm{pH}$ and particle size distribution (Table 2), SCCFs were not formed in the Bronze Age horizon at the Gulhwa site where micromorphological features appear theoretically to indicate a more degraded soil with stronger contrasting iron nodules and depleted groundmass (Table 1), whereas a higher abundance of SCCF is seen in the relatively young paddy soil of historical and modern age in the same soil profile; here there is more iron-staining and rare iron-manganese nodule development. Formation of nodules in situ appears to have have taken longer than staining, so that the decrease of nodules and increase in iron staining under the same conditions of environment might reflect the shorter period of water saturation in this case. In short, this simple comparison leads us to assume that hydromorphic degradation by wetting and drying might be insufficient to initiate the formation of SCCF.

At least, it might reflect redoximorphic regime changes in the historical and modern paddy soils whether that is irrigation regime or paleohydological changes. In the historical period, there was renewed nation-wide cultivation scheme called 'watery cultivation' with more frequent flooding-drainage phases. Thus it is suggested that SCCF formation may be linked to the influence of ferrolysis, which often takes place in artificially managed periodic wet and drying cycles. Furthermore, $\mathrm{pH}$ is neutural or acidic in our samples where ferrolysis is more, effective whereas the probable effect of ferrolysis on short-term paddy soils in calcareous environments has been questioned (Boivin et al., 2002). The formation of secondary chlorite (Van Ranst \& De Coninck, 2002) as evidence for ferrolysis, is also doubted. Other secondary minerals such as pyrite and siderite expected to be found under the redoximorphic conditions (Bouma et al., 1990) are not clearly observed. It might imply that local geomorphic, soil, ecological conditions, and cultivation processes are the variables in manifestation of certain processes such as ferrolysis.

In order to exclude equifinality (see Goldberg and Macphail, 2006, 356), other minor causes were considered, such as the separation of sorted coarse silt and finer particles as a result of 
freeze/thaw effects (Ellis \& Mellor, 1995; Williams \& Smith, 1989), and the change in silicon content caused by dissolution of biogenic silica, or phytoliths (Cornelis et al., 2010; Lucas, 2001). There is no contextual evidence to suggest that these factors are the primary drivers for enhancing SCCF formation. Thus SCCF development paddy soils requires further investigation.

Accordingly, the formation of SCCF type Y may be associated as an early phase of translocation of incompletely iron-leached clay, or was altered after deposition. The former process may explain the presence of many SCCF type Y in the lower part of the soil profile at Pyunggeo (i.e. in the prehistoric/Three Kingdoms and Unified Silla periods, 3th-10th centuries AD), whereas the latter process may explain the presence of both SCCF types X and $\mathrm{Y}$ in the upper part of the soil profile during the later periods of use of paddy soils. When a soil is disturbed, a re-organized soil structure develops which is characterised by abundant dusty clay coatings throughout the groundmass. The longer and more often a soil is cultivated, particularly one with a high groundwater regime, the more it becomes sorted, fragmented and re-worked. This leads to the formation of the silty clay concentration features throughout the groundmass. Thus these features are considered to be one of the characteristics of paddy soils.

\section{Implications for Archaeology}

This limited study of ancient paddy fields provides opportunity to observe how soil has changed in excavated ancient silty loamy paddy soil contexts beyond the well-known phenomena of gleying, and has demonstrated the presence of anomalous dusty clay concentration features. At both sites, the Bronze Age cultural layer occurs as an arable paddy field developed from river alluvium, characterised by a highly disturbed soil as shown by the presence of various textural pedofeatures. Ubiquitous redoximorphic features point to alternating wet and dry environments. At the Pyunggeo site, anomalous dusty clay features SCCF have begun forming, although the possibility of welding with the overlying historical period paddy soil cannot be ruled out.

In the historical paddy soil, both sites clearly exhibit the appearance of SCCF under redoximorphic conditions, as indicated by iron-manganese nodules and staining, and a massive microstructure with polyconcave porosity due to water saturation-induced slaking/soil dispersion processes. In addition, various other textural pedofeatures including crusts are formed together with SCCF, and their co-existence persists in the pre- modern to modern paddy soils in the Pyunggeo site and in one section of the Gulhwa site. This observation is corroborated by both excavated paddy field systems and flooding schemes of wet-rice farming recorded in the historical literature. This correlation might indicate that SCCF formation is essentially anthropogenic. In fact, in the pre-modern and modern paddy field layers, more varied SCCF types formed more often.

In conclusion, it can be stated that perhaps SCCF should be considered as indicators of intensive soil disturbance associated with cultivation activity, and in particular, soils cultivated under an irrigation regime. Alternatively, SCCF may just reflect the longevity of land use as irrigated and cultivated land through the periodic movement and accumulation of iron and silica. Thus it can be demonstrated that silty clay concentration features are consequent on irrigation in a managed agricultural landscape. They certainly share some characteristics with other pedofeatures caused by wetting and drying and by dry land cultivation, but are not identical to any of them. However, the suggestion that the early stage 
of ferrolysis is responsible for the formation of silty clay concentration features as altered clay structures associated with paddy rice farming, requires further research. This must be done with various types of ancient and modern paddy soil samples, and especially in highly calcareous soils, in order to understand hydromorphic processes and the phenomenon of concentration of fine particles. Experimental work to create silty clay concentration features by irrigation under controlled soil conditions and X-ray diffraction studies on clay mineralogical composition may be possible methods with which to investigate further this type of feature. The suggestions put forward to explain the formation of these silty clay concentration features are only hypotheses at this stage. Indeed proving the exact formation processes at work in association with particular paddy rice farming cultivation methods will require much more investigation and a broader dataset. This paper reporting the silty clay concentration features, lays emphasis on the possible presence of unknown probable anthropogenic pedofeatures and other soil characteristics associated with paddy rice cultivation, in order to identify such land use.

\section{ACKNOWLEDGEMENTS}

The Gyeongnam (Kyungnam) Development Institute, Ulsan Cultural Property Institute and Chungcheong Cultural Property Institute (South Korea) provided soil samples, excavation data, and photographs for this research. Soil samples for soil micromorphological and geophysical analyses were prepared and examined at the McBurney Geoarchaeology Laboratory and the Physical Geography Laboratory, University of Cambridge (the UK), and Dr. L.M.V. Smith (University of Cambridge) for advice on mineralogy, University of Cambridge (the UK). EDS and micro-probe analyses were conducted at the Institute of Archaeology, University College London (UK), aided by Kevin Reeves. Institute for Archaeology and Environment, Korea University (South Korea) assisted generating maps of sites. The authors wish to thank the reviewers and editors for comments and advice. 